\author{
김수진 $^{1 \dagger}$, 박서준 ${ }^{\dagger}$, 정성민 ${ }^{1 *}$, 노정호 ${ }^{3}$, 허윤영 ${ }^{1}$, 남종철 $^{1}$, 박교선 $^{4}$ \\ ${ }^{1}$ 국립원예특작과학원 과수과 \\ ${ }^{2}$ 국립원예특작과학원 기술지원과 \\ ${ }^{3}$ 국립원예특작과학원 기획조정과 \\ ${ }^{4}$ 국립원예특작과학원 온난화대응농업연구센터
}

‘청수’ 포도의 수형에 따른 수체 생육 및 과실 특성

\title{
Growth and Fruit Characteristics of 'Cheongsoo' Grape in Different Trellis Systems
}

\author{
Su Jin Kim ${ }^{1 \dagger}$, Seo Jun Park ${ }^{2 \dagger}$, Sung Min Jung ${ }^{1 *}$, Jeong Ho Noh ${ }^{3}$, Youn Young Hur ${ }^{1}$, Jong Cheol Nam ${ }^{1}$, and Kyo Sun Park ${ }^{4}$ \\ ${ }^{1}$ Fruit Research Division, National Institute of Horticultural \& Herbal Science, Suwon 440-706, Korea \\ ${ }^{2}$ Technology Service Division, National Institute of Horticultural \& Herbal Science, Suwon 440-706, Korea \\ ${ }^{3}$ Planning and Coordination Division, National Institute of Horticultural \& Herbal Science, Suwon 440-706, Korea \\ ${ }^{4}$ Agricultural Research Center for Climate Change, National Institute of Horticultural \& Herbal Science, Jeju 690-150, Korea
}

\begin{abstract}
Trellising is an important cultural practice that affects grape quality and yield. Some grape cultivars require different trellising under different climate and soil conditions. To find suitable trellis conditions for grape cultivar 'Cheongsoo', we measured growth and fruit characteristics with three different trellis systems: curtain, Geneva double curtain (GDC), and modified T. The maximum light exposure of clusters in the curtain, GDC, modified T trellis systems was $670,1,654$, and $1,649 \mu \mathrm{mol} \cdot \mathrm{m}^{-2} \cdot \mathrm{s}^{-1}$, respectively. However, there was no difference in air temperature among the three trellis systems. $\mathrm{Net}^{\mathrm{CO}_{2}}$ assimilation rate at $1,500 \mu \mathrm{mol} \cdot \mathrm{m}^{-2} \cdot \mathrm{s}^{-1}$ light intensity was $13.4,13.7$, and $8.7 \mu \mathrm{mol} \cdot \mathrm{m}^{-2} \cdot \mathrm{s}^{-1}$ in curtain, GDC, and modified T trellis systems, respectively. Trunk cross section area (TCSA) and bud burst rate were not significantly different among the three systems. Shoot number was 31.3, 47.0, and 37.0 in curtain, GDC, and modified T trellis systems, respectively. The shoot length was higher (243.9 $\mathrm{cm})$ in the modified $\mathrm{T}$ trellis system than in the single curtain $(171.1 \mathrm{~cm})$ and GDC $(151.5 \mathrm{~cm})$ systems. Interior leaf number and leaf layer number were higher in the GDC system, in which there are two primary branches, in comparison to the modified $\mathrm{T}$ and curtain systems, which utilize one primary branch. Primary leaf area and lateral leaf area were significantly higher in the modified $\mathrm{T}$ trellis system in comparison to the GDC system. Berry weight, length and diameter, and total soluble solids were not significantly different among the three trellis systems. However, cluster weight and cluster number per tree were significantly higher in GDC. Titratable acidity was significantly lower in GDC. Collectively, our data suggest that the GDC trellis system is preferable for grape 'Cheongsoo' to maintain fruit quality and quantity in Korea.
\end{abstract}

Additional key words: curtain, fruit cluster number, fruit weight, Geneva double curtain, modified $\mathrm{T}$ trellis

\section{서 언}

우리나라 포도 재배면적은 약 $17,000 \mathrm{ha}$ 로 이 중 노지재배
는 약 $15,000 \mathrm{ha}$, 시설 재배는 약 $2,000 \mathrm{ha}$ 로 전체 포도의 총 생산량은 약 30만톤이다(Korean Rural Economic Institute, 2012). 현재 수입 포도는 5월부터 판매되기 시작하며 2012

\footnotetext{
*Comesponding author: fizzfizz@korea.kr

${ }^{\dagger}$ These authors contributed equally to this work.

※ Received 2 September 2013; Revised 19 February 2014; Accepted 2 April 2014. 본 논문은 농촌진흥청 바이오그린21사업단(No. PJ008213032013)

의 연구비지원으로 수행된 연구임.

(C) 2014 Korean Society for Horticultural Science
} 
년도 수입량은 약 60,000 톤으로 국내생산량의 $20 \%$ 에 육박 하고 있다(Korea Customs Service, 2013). 국내 생식용 포도 의 주 품종은 캠벨얼리로 독특한 향(Foxy flavor)과 산미가 높은 특징으로 인해 수입산 포도와 확연하게 다른 특성을 보이고 있으나, 점차 수입 포도의 다양한 색깔, 껍질째 먹는 편리성, 큰 과립 등과 같은 장점으로 인해 국내산 포도의 소 비 시장이 정체되고 오히려 그 점유율이 낮아지는 추세이다.

이와 같이 정체된 국내산 포도 소비 시장을 활성화하기 위한 여러가지 방법 중 포도주를 양조하는 방법이 고려되고 있다(Kim et al., 2005). 고품질의 포도주 생산을 위해서는 품종 자체의 당도가 높고 산 함량이 적당해야 하는데 고품 질의 유럽종 양조용 포도 품종들은 추위에 약한 품종들이 많아 겨울철 동해 피해를 받을 수 있어 우리나라와 같이 $-20^{\circ} \mathrm{C}$ 가 하루 이상 지속되는 곳에서 재배가 어렵다(Wolf and Cook, 1994). 이러한 환경적인 제약을 극복하고자 국내 재배가 가능한 국내 육성 포도 품종중에서 생식용뿐 아니라 양조 적성이 우수한 백포도주용 품종으로 ‘청수’를 1993년 최종적으로 선발하여 현재 보급중이다.

포도는 수관 내외부의 광환경이 수확량과 과실의 성분함 량(Dokoozlian and Kliewer, 1995a; Smart and Robinson, 1991), 과실 성숙 및 내한성(Howell et al., 1991)을 결정짓는 데, 가장 중요한 요인이다. 또한 외부 광도뿐 아니라 어떤 수형을 선택하느냐에 따라 수관 내 광 환경은 물론 바람 및 습도 환경이 달라질 수 있으며(Kliewer and Smart, 1989; Louarn et al., 2008; Reynolds et al., 2004; Zoecklein et al., 2008), 이를 위해 수체의 생육 특성을 고려한 수형 구성이 중요하다(Bayougian et al., 2012).

우리나라의 포도 재배는 생식용으로의 생산이 대부분으 로 과실의 외관을 중요시하기 때문에 순지르기, 알솎기, 봉 지씨우기 등 여러 재배적인 관리가 이루어지며, 이와 같은 농작업에 투하되는 노동력이 많은 비중을 차지하고 있다 (Kim and Chung, 2000; Kim et al., 2002). 이와 같은 문제를 해결하기 위해 포도 품종별 수체 특성에 따른 여러 수형이 연구되고 있으나(Gladstone and Dokoozlian, 2003; Jackson, 1980 ) 국내에서 선발한 '청수' 품종에 대한 수형에 관한 연 구는 전무한 실정이다.

따라서 본 연구는 포도 ‘청수’ 품종의 풍산성인 착과 특징 을 살리면서 재배적인 관리가 용이한 생력형 수형을 적용하 기 위해 개량일자형(modified T trellis), 커튼형(curtain), 이 중커튼형(Geneva double curtain; GDC) 수형을 각각 구성하 고 재배하여 그 효과를 평가하였다.

\section{재료 및 방법}

\section{시험 재료 및 수형 조성}

본 시험은 농촌진흥청 국립원예특작과학원 이목동 소재 의 시험 포장에서 재식거리 $2.7 \mathrm{~m} \times 3.0 \mathrm{~m}$ 로 재식된 4 년생 '청수' 품종(Seibel $9110 \times$ Himrod Seedless)을 대상으로 하 여 수행하였다.

시험 수형은 개량일자형, 커튼형, 이중 커튼형으로 조성 하였다. 개량일자형은 주지 유인선의 높이를 지상 $1.4 \mathrm{~m}$ 에 설치한 후 재식 1 년차에 신초를 주지 유인선으로 유인하여 수형을 구성하였다. 커튼형은 $1.7 \mathrm{~m}$ 높이에 주지 유인선을 설치하고 1년차에 신초를 유인하여 수형을 구성하였다. 이 중 커튼형은 커튼형과 마찬가지로 지상으로부터 $1.7 \mathrm{~m}$ 높이 에 주지 유인선을 비가림 기둥을 사이에 두고 $120 \mathrm{~cm}$ 폭으로 2 개를 설치하고, 재식 1 년차에 한쪽 방향으로 유인하여 주 지를 구성하고 2년차에 반대쪽에 새로운 신초를 받아 나머 지 주지를 완성하였다(Fig. 1). 옆의 나무는 그림과 같이 반 대쪽의 주지유인선으로 유인하여 전체적으로 보았을 때 주 지가 2개로 이루어지도록 구성하였다. 개량일자형 수형의 관리는 발아기에 신초가 사립하여 생장하도록 하고 착립이
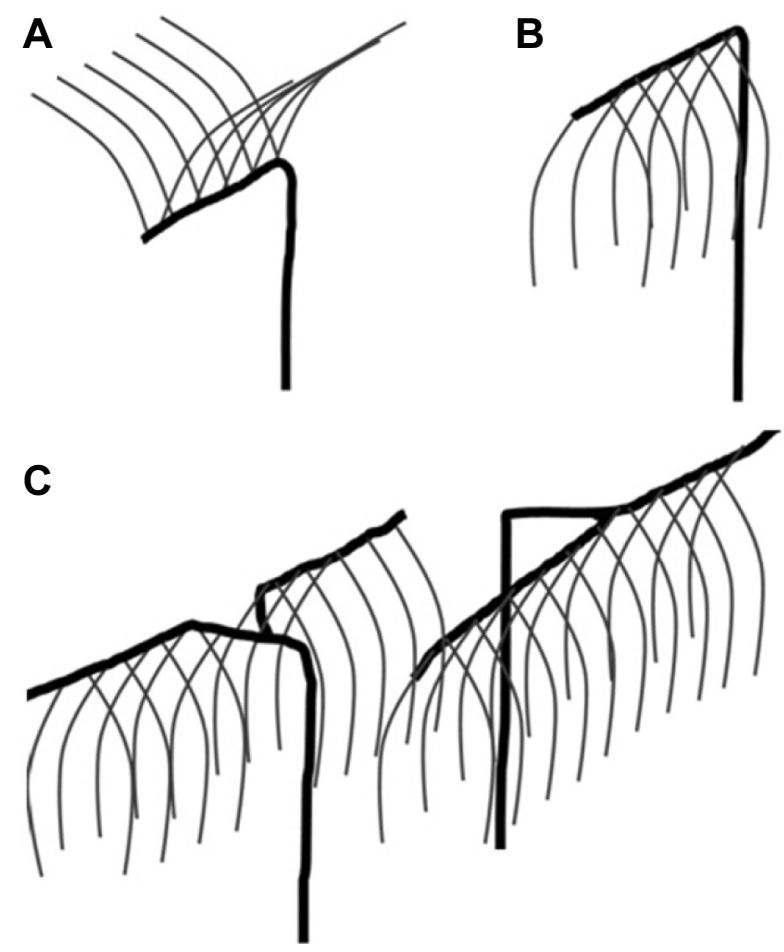

Fig. 1. Three different trellis systems in this experiment. A, modified T; B, curtain; and C, Geneva double curtain. 
된 이후 신초를 덕면에 수평으로 유인하여 관리하였다. 커 튼형과 이중커튼형은 신초가 8-9엽 정도 생장하였을 때 신 초를 기부쪽으로 비틀어 신초의 방향이 아래로 향하도록 하 여 신초의 무게로 스스로 아래쪽으로 향하도록 관리하였다. 착립이 된 이후 각 모든 신초가 아래 방향을 향하도록 신초 를 관리하였고, 세 수형 모두 부초는 주기적으로 제거해 주 었으며 별도의 알솎기, 착과량 조절은 수행하지 않았다.

\section{기상 환경 및 광합성}

과실이 위치한 부분의 광투과율을 측정하기 위해 광량센 서(Silicon pyranometer sensor, Spectrum Tech. USA \#3670I) 를 사용하여 유효광량자속밀도(photosynthetic photon flux density, PPFD)를 측정하였고 엽면 수분센서(Leaf wetness sensor 3666, Spectrum Technology, Inc., USA)로 동일 위치 의 엽면 수분량을 측정하였다. 센서는 나무의 $1.6 \mathrm{~m}$ 높이로 과실부분 주위에 근접한 잎을 제거하여 광량센서가 잎 그림 자의 영향을 받지 않도록 설치하였고, 데이터는 데이터 로 거(Watchdog 1450, Spectrum Technology, Inc., USA)에 부 착된 온습도 센서를 이용한 온습도 데이터와 함께 1 시간 간 격으로 착립된 직후인 6월 중순부터 수확이 끝난 8월 말까 지 측정하였다.

이산화탄소동화율은 일사량이 최고로 높은 오전 11시에 서 1 시 사이에 맑은 날 완전히 전개된 잎을 대상으로 광도 $1,500 \mu \mathrm{mol} \cdot \mathrm{m}^{-2} \cdot \mathrm{s}^{-1}$, 이산화탄소 농도 $360 \mathrm{ppm}$ 로 설정한 생장 상에 30 분간 광적응시킨 후 광합성측정기(LI-6400, Li-Cor., USA)을 이용하여 측정하였다.

\section{생육 특성}

수형에 따른 발아율 차이는 각 수형별 시험 처리구의 전 체 눈에 대한 발아 신초 수를 조사하여 측정하였다. 수형에 따른 수세를 비교하기 위해 모든 수형 처리구의 지상 $1 \mathrm{~m}$ 지점의 주지의 종경, 횡경을 측정하여 주지횡단면면적(trunk cross section area, TCSA)을 구하였다. 또한 신초의 세력을 확인할수 있는 전년도 결과모지의 직경을 수형별로 각 주 당 신초 10 개를 조사하였다. Ponit quadrat 분석(Smart and Robinson, 1991)은 수관 내 엽의 밀도를 측정하기 위한 방법 으로 수형별로 총 50지점을 무작위로 선정하여 막대를 수관 내로 수직으로 넣었을 때 잎이 막대에 닿는 개수를 세어 leaf layer number(LLN)를 측정하였다. 엽면적은 잎의 횡경에 따 른 엽면적의 회귀식을 우선 구한 뒤 각 수형별로 주당 10 개 신초의 잎 횡경을 조사하여 계산하였다.

\section{과실 특성}

과실은 8월에 수확하여 각 주당 수확량을 조사하였다. 각 시험 처리구당 무작위로 추출한 과방 10 개를 대상으로 과립 중을 측정하였고, 과립의 종경 및 횡경은 24 립을 임의로 채 취하여 3 반복하여 조사하였다. 가용성고형물(total soluble solids, TSS) 함량은 무작위로 10 개의 과립을 선택하여 거즈 2겹을 이용하여 착즙한 후 굴절 당도계(PAL-1 Atago, Tokyo, Japan)를 이용하여 측정하였다. 적정산도(titratable acidity, $\mathrm{TA})$ 는 동일한 과즙을 자동산도분석계(Titroline easy, Schott, Germanay)를 이용하여 측정한 후 tartaric acid 함량으로 환 산하여 표기하였다. 가용성고형물 함량과 산 함량은 총 3 반 복으로 측정하였다.

\section{통계분석}

실험결과의 통계처리는 공개용 통계소프트웨어인 R program (Ver 2.13.0)의 통계분석패키지 'Rcmdr'(Ver 1.6-4)을 이용 하여 분산분석을 하였고, 처리간 유의성은 Tukey’s honestly significant difference test를 통해 $0.05 \%$ 수준에서 검증하 였다.

\section{결과 및 고찰}

\section{기상 환경 및 광합성 특성}

‘청수’ 품종의 개량일자형, 커튼형, 이중커튼형 세가지 수 형에 따른 광 환경을 비교한 결과 수광량이 높은 수형은 커튼 형, 이중커튼형, 개량일자형 순이었다(Fig. 2). 과실착과 부위 의 최대 광량의 경우 개량일자형은 약 $670 \mu \mathrm{mol} \cdot \mathrm{m}^{-2} \cdot \mathrm{s}^{-1}$ 인데 비해 커튼형과 이중커튼형은 약 1,654 와 $1,649 \mu \mathrm{mol} \cdot \mathrm{m}^{-2} \cdot \mathrm{s}^{-1}$ 로 약 2 배 이상의 광을 받는 것으로 조사되었다. 그러나 해당위 치의 대기온도는 세 수형 모두 비슷하게 나타났다. 광합성 량을 알아보기 위해 인위적으로 $1,500 \mu \mathrm{mol} \cdot \mathrm{m}^{-2} \cdot \mathrm{s}^{-1}$ 의 광도 를 잎에 조사하였을 때 개량일자형은 이산화탄소동화율이 $8.3 \mu \mathrm{mol} \cdot \mathrm{m}^{-2} \cdot \mathrm{s}^{-1}$ 인데 비해 커튼형과 이중커튼형은 $13.4,13.7$ $\mu \mathrm{mol} \cdot \mathrm{m}^{-2} \cdot \mathrm{s}^{-1}$ 로 나타났다(Fig. 3). 개량일자형의 포도 잎은 커튼형이나 이중커튼형의 잎에 비해 낮은 광도에서 적응되 었기 때문에 상대적으로 높은 광도에서 이산화탄소동화율 이 낮게 나온 것으로 판단되었다. 간이비가림이나 비가림 시설과 같은 시설에서는 다른 과수에서도 조사된 바와 같이 노지에 비해 차광 효과가 나타나며 그로 인해 광도에 따른 이산화탄소동화율에 차이를 보이고 광포화점 또한 낮아진 다(Kim et al., 2011). 본 실험결과 커튼형이나 이중커튼형 


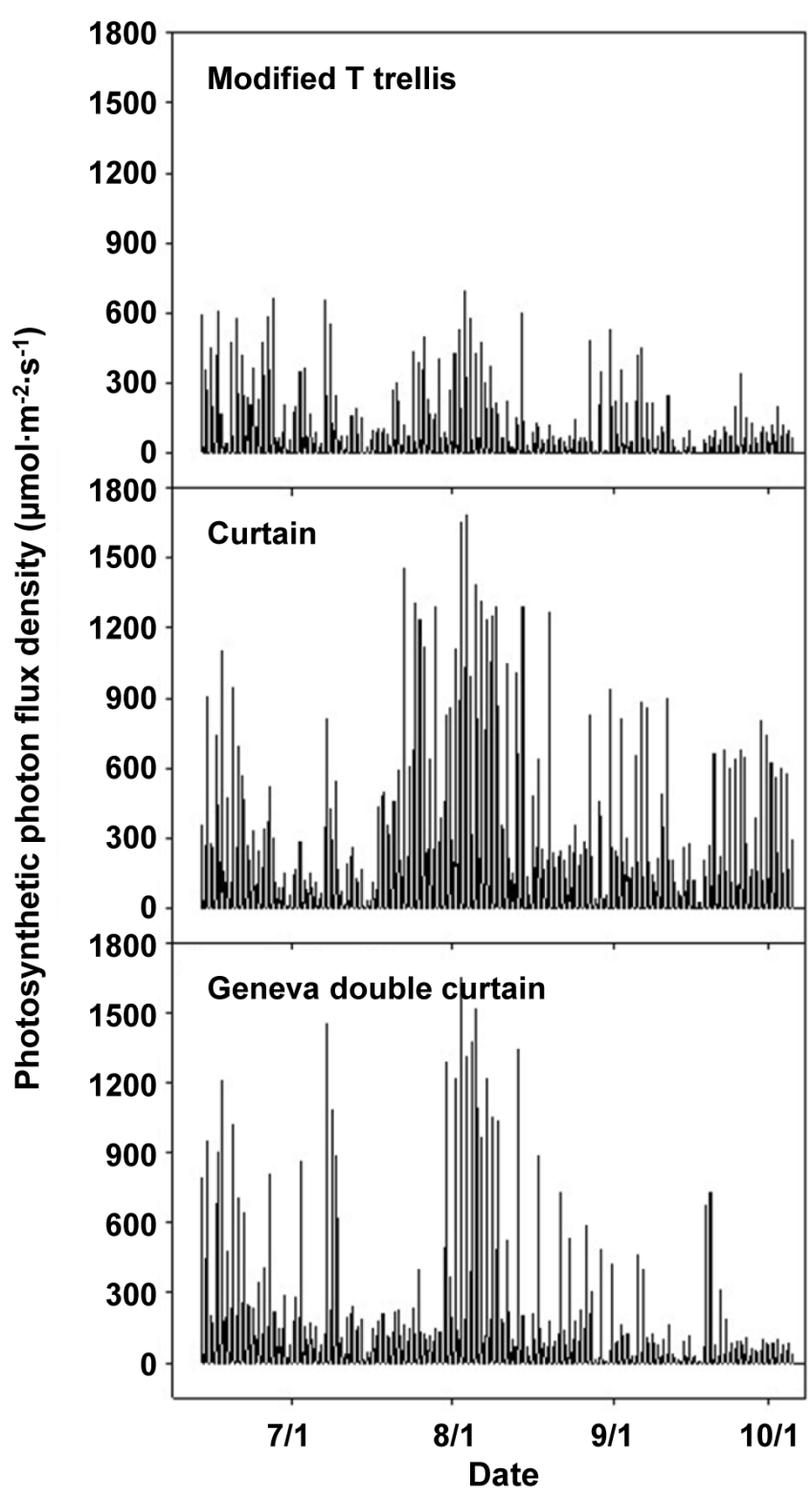

Fig. 2. Change of Photosynthetic photon flux density in grape 'Cheongsoo' by different training systems during June to October, 2012.

은 상대적으로 높은 광도에서 적응되어 광포화점을 별도로 측정하지는 않았으나 같은 빛을 조사하였을 때 개량일자형 의 잎보다 이산화탄소동화율이 높게 나타나는 결과로 볼 때 광포화점 또한 높을 것으로 추정되었다. 본 시험과 같이 포 도 재배 시 열간간격의 조절에 의해 발생하는 그림자에 의 해 낮은 당도가 발생한다(Hedberg and Raison, 1982). 또한 커튼형과 울타리형의 비교에서 커튼형의 과실부분과 신초생 장부분의 여유공간이 더 많아 차광이 덜하며 과실착과위치

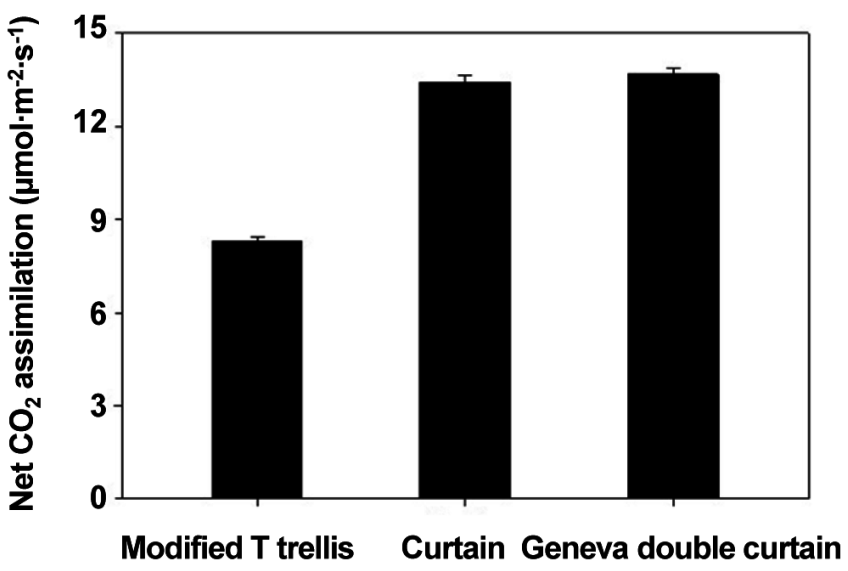

Fig. 3. Net $\mathrm{CO}_{2}$ assimilation rate of grape 'Cheongsoo' leaves under $1,500 \mu \mathrm{mol} \cdot \mathrm{m}^{-2} \cdot \mathrm{s}^{-1} \mathrm{PPFD}$ by different training systems.

의 광합성 양도 큰 차이를 보인다(Intrieri and Poni, 1993)는 보고로 볼 때 같은 간이비가림 시설이지만 수형에 따라 과실 착과위치의 엽은 커튼형이나 이중커튼형은 약 $30 \%$ 내외의 차광을 개량일자형은 $60 \%$ 정도의 차광 효과가 나타나 광합 성산물의 총량에 차이가 나타날 것으로 판단되었다(Fig. 3).

\section{생육 특성}

주지횡단면면적과 발아율은 세 수형간에 유의한 차이를 보이지 않았다(Table 1). 그러나 눈의 수와 신초 수는 54.4개 와 47.0으로 이중커튼형에서 가장 많았으며 커튼형에서는 눈의 수는 34.7 개, 신초 수는 31.3 개로 가장 적었다(Table 1). 신초의 길이는 개량일자형의 경우 $243.9 \mathrm{~cm}$ 로 가장 길었으 며 이중커튼형은 $151.5 \mathrm{~cm}$ 로 가장 짧았다(Table 1). 주지가 2 개인 이중커튼형에서는 수관 내부에 위치한 잎 수와 비율, LLN이 높게 나타난 반면 초생엽과 부초엽의 엽면적의 경우 개량일자형이 다른 수형에 비해 월등하게 높게 나타났다 (Table 2). 개량일자형은 신초를 위로 뻔게 하는 수형으로 (Fig. 1) 생육이 왕성한 품종 특성을 가진 ‘청수'의 경우 신초 생장이 많아지고 엽면적이 커지는 등의 영양 생장이 지나치 게 많아졌음을 알 수 있었다. 또한 엽면적이 넓어 수관 내 광 노출이 $5 \%$ 정도 감소한 나무는 엽면적이 작아 겹치는 잎이 적은 나무에 비해 수관 전체상으로는 $10 \%$ 내지 그 이 상의 차광 효과를 나타낸다(Dokoozlian and Kliewer, 1995b; Gladstone and Dokoozlian, 2003). 따라서 위쪽으로 향해 개 방형의 수형을 가졌으나 품종 특성에 따라 넓은 엽면적 밀 도를 가진 개량일자형에서의 채광량이 실제적으로 커튼형 이나 이중커튼형에 비해 더욱 더 감소하게 되어 생육 및 과 
Table 1. Vine growth characteristics of grape 'Cheongsoo' between three different trellises.

\begin{tabular}{|c|c|c|c|c|c|}
\hline Trellis system & $\begin{array}{l}\text { Trunk cross section area } \\
\left(\mathrm{mm}^{2}\right)^{\mathrm{z}}\end{array}$ & Bud number & $\begin{array}{c}\text { Bud burst } \\
(\%)\end{array}$ & Shoot number & $\begin{array}{l}\text { Shoot length } \\
(\mathrm{cm})\end{array}$ \\
\hline Modified $\mathrm{T}$ trellis & $597.4 \mathrm{a}^{\mathrm{y}}$ & $41.7 \mathrm{ab}$ & 88.9 a & $37.0 \mathrm{ab}$ & $243.9 \mathrm{a}$ \\
\hline Curtain & $443.3 \mathrm{a}$ & $34.7 \mathrm{~b}$ & $90.5 \mathrm{a}$ & $31.3 \mathrm{~b}$ & $171.1 \mathrm{~b}$ \\
\hline Geneva double curtain & $362.4 \mathrm{a}$ & $54.4 \mathrm{a}$ & $88.1 \mathrm{a}$ & $47.0 \mathrm{a}$ & $151.5 \mathrm{~b}$ \\
\hline
\end{tabular}

${ }^{\mathrm{z}} \mathrm{TCSA}$ was measured $1 \mathrm{~m}$ from the ground.

${ }^{\mathrm{y}}$ Means with the same letter are not significantly different at the $5 \%$ by Tukey's HSD.

Table 2. Canopy growth characteristics of grape 'Cheongsoo' between three different trellises.

\begin{tabular}{lccccc}
\hline Trellis system & $\begin{array}{c}\text { Interior leaf } \\
\text { number }\end{array}$ & $\begin{array}{c}\text { Interior leaf } \\
(\%)\end{array}$ & $\begin{array}{c}\text { Leaf layer } \\
\text { number }\end{array}$ & $\begin{array}{c}\text { Primary leaf area } \\
\left(\mathrm{cm}^{2}\right)\end{array}$ & $\begin{array}{c}\text { Lateral leaf area } \\
\left(\mathrm{cm}^{2}\right)\end{array}$ \\
\hline Modified T trellis & $12.8 \mathrm{~b}^{\mathrm{y}}$ & $32.5 \mathrm{~b}$ & $1.30 \mathrm{~b}$ & $8,948 \mathrm{a}$ & $2,620 \mathrm{a}$ \\
Curtain & $16.5 \mathrm{~b}$ & $39.3 \mathrm{~b}$ & $1.57 \mathrm{~b}$ & $7,538 \mathrm{~b}$ & $1,693 \mathrm{a}$ \\
Geneva double curtain & $43.0 \mathrm{a}$ & $67.5 \mathrm{a}$ & $2.70 \mathrm{a}$ & $6,417 \mathrm{c}$ & $1,398 \mathrm{~b}$ \\
\hline
\end{tabular}

${ }^{\mathrm{z}}$ Point Quadrat Analysis (Smart and Robinson, 1992).

${ }^{\mathrm{y}}$ Means with the same letter are not significantly different at the $5 \%$ by Tukey's HSD.

Table 3. Fruit characteristics of grape 'Cheongsoo' between three different trellises.

\begin{tabular}{|c|c|c|c|c|c|c|c|c|c|}
\hline \multirow[b]{2}{*}{ Trellis system } & \multicolumn{3}{|c|}{ Berry } & \multirow{2}{*}{$\begin{array}{c}\text { Fruit cluster } \\
\text { weight } \\
\text { (g) }\end{array}$} & \multirow[b]{2}{*}{$\mathrm{pH}$} & \multirow{2}{*}{$\begin{array}{c}\text { Total soluble } \\
\text { solids } \\
\left({ }^{\circ} \text { Brix }\right)\end{array}$} & \multirow{2}{*}{$\begin{array}{l}\text { Titratable } \\
\text { acidity } \\
(\%)\end{array}$} & \multirow{2}{*}{$\begin{array}{c}\text { Fruit } \\
\text { cluster } \\
\text { (no/tree) }\end{array}$} & \multirow{2}{*}{$\begin{array}{c}\text { Estimated } \\
\text { yield } \\
\left(\text { ton } \cdot 10 \mathrm{a}^{-1}\right)\end{array}$} \\
\hline & $\begin{array}{c}\text { Weight } \\
\text { (g) }\end{array}$ & $\begin{array}{l}\text { Length } \\
(\mathrm{mm})\end{array}$ & $\begin{array}{c}\text { Diameter } \\
(\mathrm{mm})\end{array}$ & & & & & & \\
\hline Curtain & $2.68 \mathrm{a}$ & $15.76 \mathrm{a}$ & $15.53 \mathrm{a}$ & $175.84 \mathrm{a}$ & $2.72 \mathrm{~b}$ & $17.91 \mathrm{a}$ & $0.56 \mathrm{a}$ & $97.42 \mathrm{ab}$ & 1.71 \\
\hline Geneva double curtain & $2.93 \mathrm{a}$ & $16.19 \mathrm{a}$ & $15.94 \mathrm{a}$ & $203.66 \mathrm{a}$ & $3.24 \mathrm{a}$ & $17.70 \mathrm{a}$ & $0.45 \mathrm{~b}$ & $136.80 \mathrm{a}$ & 2.79 \\
\hline
\end{tabular}

${ }^{\mathrm{z}}$ Means with the same letter are not significantly different at the $5 \%$ by Tukey's HSD.

실 특성에 영향을 미친 것으로 판단되었다.

\section{과실 특성}

과실의 특성은 착과량에서 큰 차이를 보이는데 본 시험은 수형에 따른 착립 정도와 성숙능력을 상호 비교하기 위해 계획된 만큼 수형에 따른 착과량의 변화가 예상되었다. 햇 빛에 노출된 과실이 차광된 과실에 비해 무게나 크기가 작 아진다는 여러 보고와는 달리(Crippen and Morrison, 1986; Reynolds et al., 1986), 본 연구에서는 또 다른 선행연구 (Rojas-Lara and Morrison, 1989)와 같이 과립 무게, 과립의 종경 및 횡경에서는 세 수형간 차이가 나타나지 않았다 (Table 3). 그러나 과방중은 이중커튼형에서 $203.66 \mathrm{~g}$ 으로 가 장 높았으며 개량일자형에서는 $130.10 \mathrm{~g}$ 으로 가장 낮았다 (Table 3). 이는 전년도의 눈이 차광된 수형에 비해 이중커튼 형에서 수확량과 착립이 향상되며 단위면적당 유효한 표면
적 즉 수광면적이 이중커튼형에서 증가한다는 사실(Smart and Robinson, 1991)로 볼 때 착립이 향상된 효과로 이해할 수 있다. 특히 이중커튼형의 경우 수형의 구성자체가 수세 가 강한 경우 신초가 아래방향으로 자라게 되므로 그 세력 을 약화시키는 수형으로 알려져 있다(Smart and Robinson. 1991). 나무당 과방의 수 또한 이중커튼형이 136.8 개로 개량 일자형의 86.28 개나 커튼형의 97.42 개에 비해 약 $40-60 \%$ 정 도 많았다. 따라서 $10 \mathrm{a}$ 당 수확량을 추정해보면 개량일자형 이 약 $1.12 \mathrm{ton}$, 커튼형이 1.71ton, 이중커튼형이 2.79ton으로 나타나 수형에 따른 수확량 차이가 많은 것으로 조사되었다. 그러나 과실의 당도는 세 수형간의 유의한 차이를 보이지 않 았다(Table 3). 와인을 가공할 때 과실의 $\mathrm{pH}$ 가 3.6 이상의 경 우 안전성에 문제가 생기는 것으로 알려져 있는데(Amerine and Ough, 1976) 과실의 $\mathrm{pH}$ 는 개량일자형과 이중커튼형이 비슷한 양상이었으며 커튼형에서 다소 낮게 나타났으나 
(Table 3) 세 수형에서 모두 3.6 이하로 나타나 와인 적성에 는 적합한 것으로 판단되었다. 산도는 개량일자형과 커튼형 에서 0.56-0.58로 비슷하게 나타났으며 이중커튼형에서는 0.45 로 다른 수형에 비해 유의하게 낮았다(Table 3). 이는 포도 'Vignoles' 품종의 전체적인 과실의 성숙이 낮은 주지 $(1 \mathrm{~m})$ 보 다 높은 주지(1.8m)에서 더욱 좋았다(Howell et al., 1991)는 보고와 일치한다.

따라서 수형에 따른 생장특성에서의 차이와 과실특성 그 리고 착과량을 종합할 때, '청수’ 품종은 단위면적당 수확량 을 높이면서도 과실의 품질이 저해되지 않고 지나친 신초 생장으로 인한 순지르기 작업 등의 노동 시간을 줄일 수 있 는 이중커튼형으로 수형을 관리하는 것이 적합한 것으로 판 단되며, ‘청수'와 같이 수체 생육 특성이 중간이나 왕성한 품종에 적합한 수형은 채광량이 높고 수확량이 많은 커튼형 이나 이중커튼형이 적합한 수형이라는 연구 결과와 일치한 다(Bayougian et al., 2012; Gladstone and Dokoozlian, 2003). 이러한 결과는 국내 육성 품종인 '청수’ 품종의 농가 보급 및 재배에 중요한 기초 자료가 될 것으로 판단된다.

\section{초 록}

수형은 포도 과실의 품질과 수확량에 영향을 주는 주요한 요인이다. 또한 몇몇 포도 품종들은 다양한 기후와 토양조 건에서 고유한 특성을 드러내기 위해 적합한 수형을 요구한 다. 본 연구는 '청수' 품종의 우리나라에서의 재배에 적합한 수형을 평가하기 위해 수행되었다. '청수' 품종의 수형에 따 른 광 환경을 비교한 결과 수광량이 높은 수형은 커튼형, 이 중커튼형, 개량일자형 순이었다. 최대 광량의 경우 개량일자 형은 약 $670 \mu \mathrm{mol} \cdot \mathrm{m}^{-2} \cdot \mathrm{s}^{-1}$ 인데 비해 커튼형과 이중커튼형은 약 1,654 와 $1,649 \mu \mathrm{mol} \cdot \mathrm{m}^{-2} \cdot \mathrm{s}^{-1}$ 로 나타났다. 대기온도는 세 수형 모두 비슷하게 나타났다. 광도 $1,500 \mu \mathrm{mol} \cdot \mathrm{m}^{-2} \cdot \mathrm{s}^{-1}$ 에서 개량일자형은 이산화탄소동화율이 $8.3 \mu \mathrm{mol} \cdot \mathrm{m}^{-2} \cdot \mathrm{s}^{-1}$ 인데 비 해 커튼형과 이중커튼형은 $13.4,13.7 \mu \mathrm{mol} \cdot \mathrm{m}^{-2} \cdot \mathrm{s}^{-1}$ 로 나타났 다. 주지횡단면면적과 발아율은 세 수형간에 유의한 차이를 보이지 않았다. 눈의 수와 신초 수는 54.4개와 47.0으로 이 중커튼형에서 가장 많았으며 커튼형에서는 눈의 수는 34.7 개, 신초 수는 31.3 개로 가장 적었다. 신초의 길이는 개량일 자형의 경우 $243.9 \mathrm{~cm}$ 로 가장 길었으며 이중커튼형은 $151.5 \mathrm{~cm}$ 로 가장 짧았다. 초생엽과 부초엽의 엽면적의 경우에도 개 량일자형이 다른 수형에 비해 월등하게 높게 나타났다. 수 관 내부 잎 수와 전체 잎에 대한 수관 내부 잎의 비율은 이중
커튼형이 높게 나타났다. 과립 무게, 과립의 종경과 횡경은 수 형간 차이가 나타나지 않았다. 그러나 과방중은 이중커튼형에 서 $203.66 \mathrm{~g}$ 으로 가장 높았으며 개량일자형에서는 $130.10 \mathrm{~g}$ 으 로 가장 낮았다. 나무당 과방수 또한 이중커튼형이 136.8 개 로 개량일자형의 86.28 나 커튼형의 97.42 개에 비해 많았다. 산도는 이중커튼형에서 0.45 로 다른 수형에 비해 유의하게 낮았다. 따라서 '청수' 품종은 단위면적당 수확량을 높이면 서도 과실의 품질이 저해되지 않는 이중커튼형으로 수형을 관리하는 것이 적합한 것으로 판단되며 이는 '청수' 품종의 농가 보급 및 재배에 중요한 정보가 될 것이다.

추가 주요어 : 커튼형, 송이 수, 송이 무게, 이중커튼형, 개량 일자형

\section{인용문헌}

Amerine, M.A. and C.S. Ough. 1976. Analysis of wines and musts. Acribia, Zaragoza, Spain. 158 p.

Bayougian, C.M., P.E. Read, and E. Water-Shea. 2012. Training system effects on sunlight penetration, canopy structure, yield, and fruit characteristics of 'Frontenac' grapevine (Vitis spp.). Intl. J. Fruit Sci. 12:402-409.

Crippen, D.D. and J.C. Morrison. 1986. The effects of sun exposure on the compositional development of 'Carbernet Sauvignon' berries. Am. J. Enol. Vitic. 37:235-242.

Dokoozlian, N.K. and W.M. Kliewer. 1995a. The light environment within grapevine canopies. I. Description and seasonal changes during fruit development. Am. J. Enol. Vitic. 46:209-218.

Dokoozlian, N.K. and W.M. Kliewer. 1995b. The light environment within grapevine canopies. II. Influence of leaf area density on fruit zone light environment and some canopy assessment parameters. Am. J. Enol. Vitic. 46:219-226.

Gladstone, E.A. and N.K. Dokoozlian. 2003. Influence of leaf area density and trellis/training system on the light microclimate within grapevine canopies. Vitis 42:123-131.

Hedberg, P.R. and J. Raison. 1982. The effect of vine spacing and trellising on yield and fruit quality of Shiraz grapevines. Am. J. Enol. Vitic. 33:20-30.

Howell, G.S., D.P. Miller, C.E. Edson, and R.K. Striegler. 1991. Influence of training system and pruning severity on yield, vine size, and fruit composition of Vignoles grapevines. Amer. J. Enol. Viticult. 42:191-198.

Intrieri, C. and S. Poni. 1993. Intergrated evolution of trellis training systems and machines to improve grape quality and 
vintage quality of mechanized Italian vineyards. Am. J. Enol. Vitic. 46:116-127.

Jackson, J.E. 1980. Light interception and utilization by orchard systems. Hortic. Rev. 2:208-267.

Kim, I.L., Y.L. Piao, Y.S. Hwang, and J.C. Lee. 2002. Effects of synthetic cytokinin, thidiazuron on berry size and quality of 'Campbell Early' (Vitis labruscana) grape. J. Kor. Soc. Hort. Sci. 41:75-77.

Kim, K., J. Zhao, and J. Ko. 2005. Exploring the Korean wine market. J. Hospitality Tourism Res. 29:20-41.

Kim, S.J., D.J. Yu, T.C. Kim, and H.J. Lee. 2011. Growth and photosynthetic characteristics of blueberry (Vaccinium corymbosum cv. Bluecrop) under various shade levels. Sci. Hort. 129:486-492.

Kim, W.S. and S.J. Chung. 2000. Effect of GA, ethephon, girdling and wiring treatment on the berry enlargement and maturity of 'Himrod' grape. J. Kor. Soc. Hort. Sci. 41:75-77.

Kliewer, W.M. and R.E. Smart. 1989. Canopy manipulation for optimizing vine microclimate, crop yield and composition of grapes, p. 275-291. In: C.J. Wright (ed.). Manipulation of fruiting. Butterworths, London.

Korea Customs Service. 2013. Export and import trade statistics, imported fruit report in the last decade. Korea Customs Service, Daejeon, Korea.

Korean Rural Economic Institute. 2012. Agricultural monitoring service. Agricultural Outlook Center, Korea Rural Economic Institute, Seoul, Korea.

Louarn, G., J. Dauzat, J. Lecoeur, and E. Lebon. 2008. Influence of trellis system and shoot positioning on light interception and distribution in two grapevine cultivars with different architectures: an original approach based on 3D canopy modeling. Aust. J. Grape Wine Res. 14:143-152.

Morrison, J.C. and A.C. Noble. 1990. The effect of leaf and cluster shading on the composition of Carbetnet Sauvignon grapes and on fruit and wine sensory properties. Am. J. Enol. Vitic. 41:193-200

Reynolds, A.G., D.A. Wardle, M.A. Cliff, and M. King. 2004. Impact of training system and vine spacing on vine performance, berry composition, and wine sensory attributes of Seyval and Chancellor. Am. J. Enol. Vitic. 55:84-95.

Reynolds, A.G., R.M. Pool, L.R. Mattick. 1986. Influence of cluster exposure on fruit composition and wine quality of Seyval blanc grapes. Vitis 25:85-95.

Rojas-Lara, E.A. and J.C. Morrison. 1989. Differntial effects of shading fruit or foliage on the development and composition of grape berries. Vitis 28:199-208.

Smart, R. and M. Robinson. 1991. Sunlight into wine. Winetitles, Adelaide.

Wolf, T.K. and M.K. Cook. 1994. Cold hardiness of dormant buds of grape cultivars: Comparison of thermal analysis and field survival. HortScience 29:1453-1455.

Zoecklein, B.W., T.K. Wolf, L. Pelanne, M.K. Miller, and S.S. Birkenmaier. 2008. Effect of vertical shoot-positioned, SmartDyson, and Geneva double curtain training systems on Viognier grape and wine composition. Am. J. Enol. Vitic. 59:11-21. 